\title{
Rail radar - a fast maturing tool for monitoring trackbed
}

\author{
Qing Zhang, Asger Eriksen and Jon Gascoyne \\ Zetica Rail. \\ Long Hanborough, Oxfordshire, OX29 8LH, UK \\ Email: rail@zetica.com
}

\begin{abstract}
Ground Penetrating Radar ('rail radar') technology has long been a focus for railway trackbed maintenance and renewals planning due to its non-destructive nature and its potential to offer significant efficiency savings in trackbed condition monitoring. This paper provides a brief introduction to the two main interpretation techniques (interface reflection and EM scattering) currently used to monitor railway trackbed and identify the causes of anomalous trackbed conditions. A number of survey examples and scenarios are provided and explained in detail.
\end{abstract}

Keywords- Ground Penetrating Radar; Railway Trackbed; Ballast Fouling; Electromagnetic Scattering

\section{INTRODUCTION}

In a railway trackbed, the ballast layer is designed to distribute the loading force of a passing train evenly over the formation layer to preserve a smooth ride. The ballast also acts as a drainage layer to prevent significant accumulations of moisture. The optimum ballast thickness is the thickness where ballast exerts constant and uniform pressure on the subgrade. The design thickness is a function of the load and speed of traffic. A homogenous ballast layer results in a stable and safe track. Any departure from the construction design such as changes in the thickness of the ballast layer and the degree of contamination within the ballast matrix will affect the dynamic behavior of the track-bed. Contaminated ballast causes an unstable pressure distribution on the subgrade. Good ballast materials comprise dust-free angular aggregate particles which resist vertical, lateral and longitudinal forces. Sub-ballast can help reduce the stress levels further to the subgrade. Subgrade is a pre-prepared foundation for supporting the track structure. Accurate knowledge of each layer has been increasingly seen as essential for maintenance and efficient planning of renewals.

Ground Penetrating Radar (GPR) technology has being widely recognized for its ability to non-destructively detect subsurface structures, drainage, erosion and moisture content. Recent papers have demonstrated the utility of GPR in solving a variety of problems related to trackbed characterization [1-2]. Al-Nuaimy, Eriksen and Gascoyne have shown that GPR can be used to provide rapid, objective and quantitative information about the depth and degree of deterioration of ballast with minimal disturbance to the actual track-bed [3]. Ballast quality calibration using non-contact methods of calculating the in-situ propagation velocity of electro-magnetic (EM) waves through ballast has been explored by Gallagher, Leiper and Forde [4]. The use of a multi-channel road-rail GPR for improved productivity and reliability of ballast inspection has also been presented by Eriksen in [5]. Significant effort has also been focused towards the extraction of meaningful physical interpretations from the GPR data using novel signal/image processing and pattern recognition techniques. Shihab, Nuaimy and Huang have presented a Neural Net-work target identifier based on statistical features of GPR signals [6].

This paper provides a comprehensive review of the latest applications of GPR for trackbed maintenance and problem identification.

\section{GPR INTERPRETATION THEORY}

\section{A. Interpretation based on interface reflections}

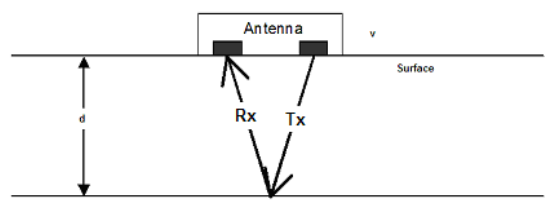

So far the most widely used techniques for the GPR signal interpretation is to analyze the reflection from the interface between two media layers, specifically for railway trackbed, the ballast/subballast interface and ballast/subgrade interface. Because of the dielectric contrast between two materials, a reflection of the GPR pulse will occur at the interface and be recorded at the receiver with a reference to time. The time that the GPR pulse travels from the transmitter antenna, goes through layers of media, reflects back to the receiver, is called two way travel time (TWTT). It is vital important parameter for determining the physical properties of the media because it is a combination of the thickness and velocity of each layer. In the case of a single, homogeneous layer the velocity is related to the relative permittivity $\mathcal{E}_{r}$ by

$$
v=\frac{c}{\sqrt{\varepsilon_{r}}}
$$

where $c$ is the speed of light in free space. For homogenous media, the dielectric constant $\mathcal{E}$ can be calculated from the 
signal amplitude at the reflection point based on general transmission wave theory [7].

However, railway ballast layer is made of crushed stones in different size and air voids. Hence transmission wave equations have very limited use in the non-homogenous ballast layer. Efforts have been made to experimentally derive the dielectric constant values for ballast in different conditions, with various fouling levels and moisture levels [8]. These methods work well when ballast conditions are known. However, an inservice trackbed is typically an unknown mixture of different material with different particle sizes and variable moisture content.

Alternative methods of determining velocity such as Common Midpoint (CMP) or Wide Angle Refraction Reflection (WARR) currently have limited application in the rail environment as they can only be implemented if a well-defined reflection boundary (such as the ballast / sub-ballast interface) is visible in the data and work only at slow-acquisition speeds. Recent advances in high-speed data acquisition mean that routine use of CMP or WARR may become reality in the near future.

At present methods to empirically derive dielectric values provide the most practical means of calculating layer thicknesses. This is best done using information obtained from trial pits or ballast sampling or by hyperbolic curve fitting.

As well as the TWTT to the reflecting interface the amplitude of the signal reflected at the interface is also measured. The reflection strength is controlled by the dielectric properties of the materials either side of the interface. The ratio between the energy transmitted and reflected at the boundary is a function of the impedance of the two materials,

$$
\rho=\frac{\eta_{2}-\eta_{1}}{\eta_{2}+\eta_{1}}
$$

where $\rho$ is the reflection coefficient, $\eta_{1}$ is the impedance of first layer material and $\eta_{2}$ is the impedance of second layer material. Observed variation in the reflection strength along the interface may either be due to a change in the material above or below the boundary.

\section{B. Interpretation based on EM scattering}

A recent important advance in the GPR interpretation for railway ballast is based on EM scattering theory [9]. Basically, a resonance behavior is observed in the GPR high frequency response when the signal pulse travels through clean ballast aggregate. This phenomenon is known as Mie scattering and occurs when the dimensions of particles or inclusions in a material are on the same order of scale as the EM wavelength.

The source of the scattering is called scatter. In railway ballast, the scatters are the air voids between the ballast particles. Typically the size of these voids in clean ballast varies from $11 \mathrm{~mm}$ to $29 \mathrm{~mm}$ [10] which results in a dominant scattering response at frequencies of around $2 \mathrm{GHz}$ [11]. The recorded GPR response is the superposition of multiple scattering reflections from the air voids.

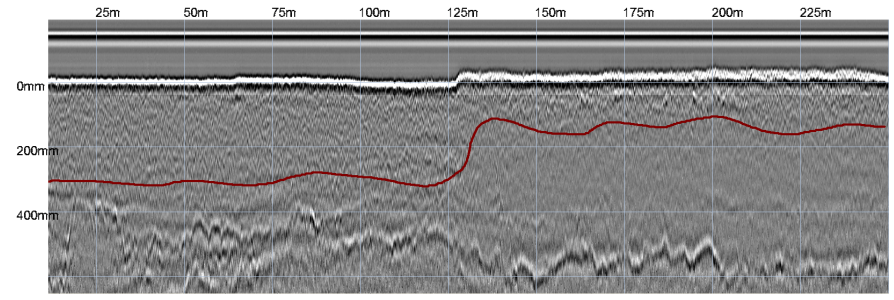

Figure 1. Example showing the scattering effect.

This theory stands as long as there is air in the ballast void spaces. When these spaces become filled up with fine particles, either through deterioration of the ballast or through the introduction of external fine particles such as coal dust or mud $\&$ silt, the scattering response disappears. Differentiation and interpretation can be done by examining the signal patterns in the radar image. Figure 1 shows an example of the scattering effect. The red curve defines the boundary of the scattering and is termed the scattering envelope.

The advantages of the EM scattering method over conventional reflection-based interpretation methods are that it is not reliant on the dielectric properties of the materials (which are difficult to determine) and is independent of any variation in the nature of the sub-grade materials. The level of scattering at a particular depth is a function of the void space within a small volume at that depth.

The amplitude response at the reflection boundary only provides information on the relative difference between the materials either side of the boundary and is thus subject to property changes in both the upper and lower layers. A change in moisture levels at the interface, an increase in fouling in the overlying ballast or a change in the nature of the sub-grade materials could all result in a similar amplitude response.

\section{A VERSATILE TOOL FOR TRACKBED MAINTENANCE}

Trackbed is a man-made structure, which contains natural material, soil, sand, stones, as well as artificial components, such as sleepers, rails and clips. The GPR signal responds to almost all these features, making it a versatile tool in trackbed maintenance and also asset management. Nevertheless, the interpretation of the GPR response to different features is not without challenge. In the following we present typical examples and scenarios that have been encountered in interpreting GPR signal for trackbed evaluation. 


\section{A. Ballast layer geometry}

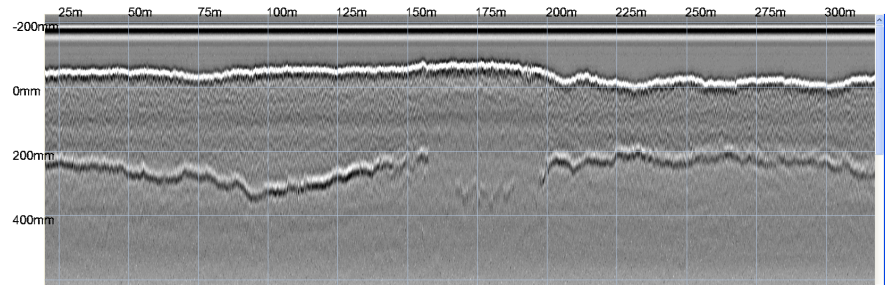

Figure 2. A GPR scan example showing a clear boundary between the clean ballast layer and the underlying sub-grade layer. A reduction in reflection strength and an increase in the TWTT observed near the centre of the image identify an area of anomalous trackbed.

Ballast layer mapping is based on the interface reflection theory to calculate the thickness of each layer. As explained in the previous section, because of the difficulties in calculating the dielectric constant within ballast, this method only provides an estimate of depth with an associated error range. It does require the calibration by ballast sampling cores if a very accurate measurement of ballast depth is deemed necessary. However, it allows us to identify those problematic areas, which have significant variation and disturbance in the GPR response, based on a local and detailed interpretation.

Figure 2 is a good example of development of a localised problem between two sections of clean ballast. The reflection at the interface between the ballast and subballast in the middle area is much weaker than the two sides and the two-way travel time to the interface is larger. In fact, this could mean one of two things, either the sub-grade changes in the centre (becoming more granular hence closer to the ballast dielectric) thus reducing the reflection amplitude, or the ballast fouling is higher, resulting in a reduction in the dielectric contrast with a silty sub-grade material.

Figure 3 presents an example of more complicated trackbed structures. This is not uncommon in heavy haul lines, where ballast life is shorter and regular maintenance is conducted, so that new ballast layer is lay down on top of old crushed ballast layer. Interestingly, the radar image displays a history of ballast renewal.

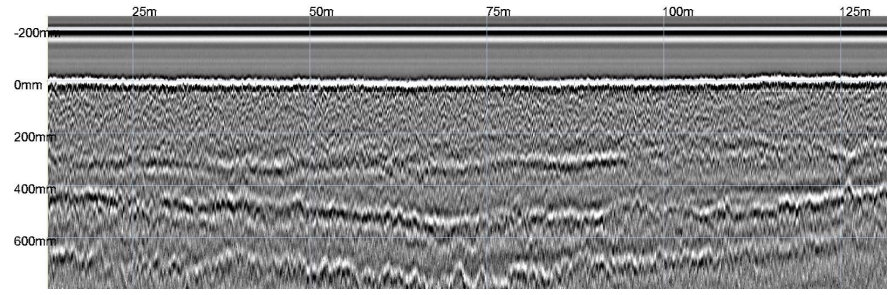

Figure 3. Example with more than one reflections from multiple interfaces showing the history of the trackbed maintenance. Surface Interface

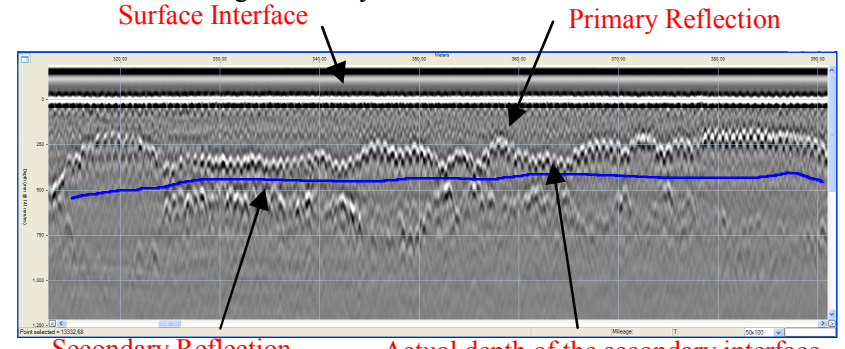

Secondary Reflection
Figure 4. Typical mirror effect caused by the fluctuation of the first interface and the dielectric contrast between two materials.

Another phenomenon commonly observed is the mirroring effect between two interfaces, as illustrated in Figure 4. The primary reflection line indicates the bottom of the first layer. The secondary reflection appears to mirror the primary reflection to a certain degree. This is not caused by the geometry of the second layer. Rather it is a result of the fluctuation of the first interface and the dielectric contrast between the materials within either layer $[12,13]$. The real geometry of the bottom of the second layer is indicated by the blue line in the figure. If the second layer material has a dielectric value very close to the first layer material, the mirroring effect is very limited. The perfect mirror occurs when the EM velocity in the second layer is half that of the overlying layer. This requires a dielectric value of the second layer four times of that of the first layer. As the dielectric value of the second layer increases, the mirror effect is magnified. The same kind of mirroring effect can be observed in the surface reflection when the track is covered by a layer of other material.

Figure 5 is an example of radar survey conducted on a track after heavy snow. Because the dielectric contrast between dry snow (3-4) and trackbed ballast (around 4-5 in dry condition) is small, the mirroring effect is limited.

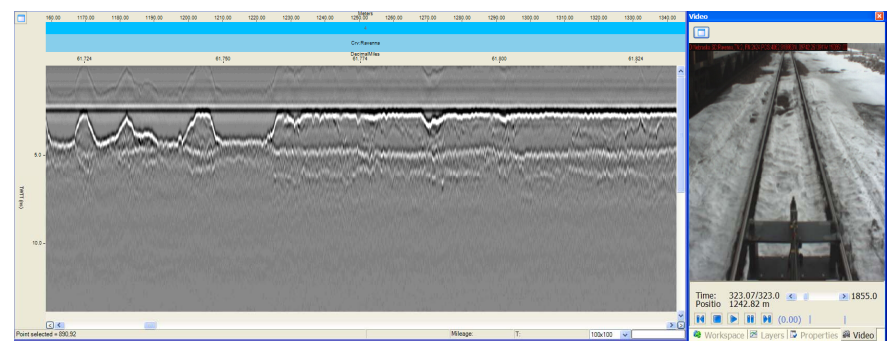

Figure 5. Effect of snow accumulation on railway tracks (the video image is taken from a camera mounted on the back of the hy-rail survey vehicle).

\section{B. Moisture Detection}

Trapped moisture is an indication of drainage problems and thus a high priority for maintenance works. The fine particle mixed with water will be clogged in the air voids and contaminate the ballast and downgrade the function of ballast layer. In fact, a very important function of ballast is the free draining of water

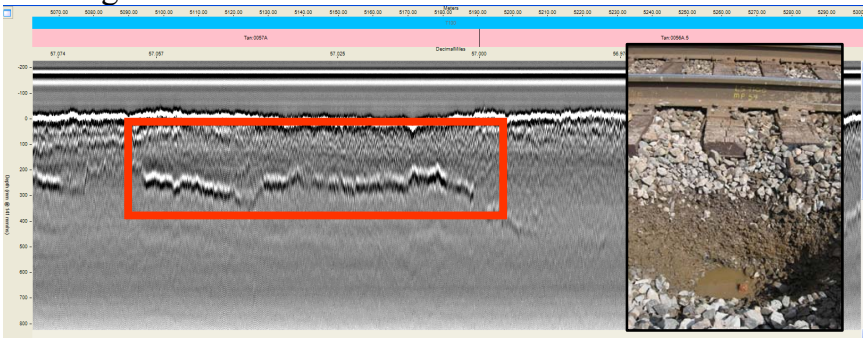

Figure 6. Water trapped in track-bed shoulder

Figure 6 is an example where water has been trapped at the bottom of the trackbed layer due to fine particles and fouled 
ballast, although by looking from the surface, the ballast stones look perfect. Without digging out, one would not be able to tell the problem underneath. In the GPR radar image the problem area is identified by a localised increase in the amplitude of the reflection at the ballast / fouled ballast interface.

The development of surface wet-beds (also known as mud spots in the UK or bog holes in Australia) is another target for automatic mapping using GPR.

\section{Asset Identification}

Apart from monitoring changes in the geometry of the primary trackbed layers, surface assets can also be mapped. These include but are not limited to AWS (automatic warning system) magnets, ATP (automatic train protection) element, SNC rail crossings, etc. Figure 7 illustrates some examples of these features identified in the GPR signal with an accompanying photograph.

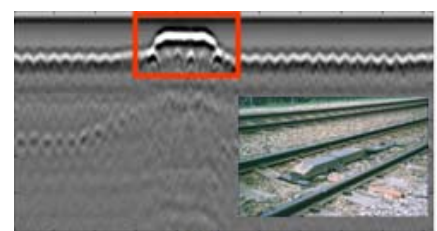

(a)

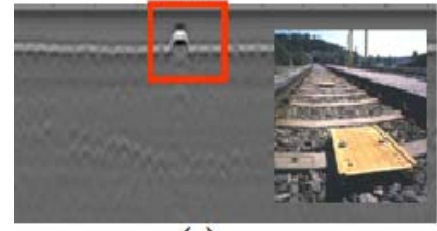

(c)

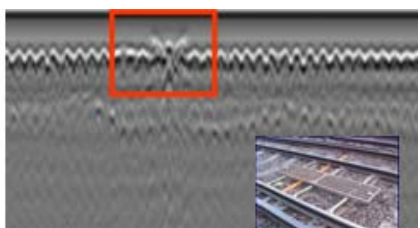

(b)

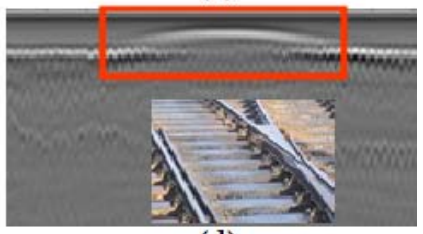

(d)
Figure 7. Examples of features identified by GPR on the railway line, (a) Automatic Warning System (AWS) magnet, (b) Train Protection and Warning System (TPWS), (c)Automatic Train Protection (ATP) and (d) SNC rail crossing).

Structures are also detectable in radar scans. Figure 8 shows two examples of bridges identified along the radar survey route.

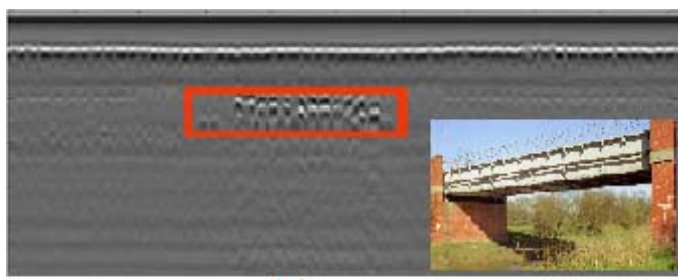

(a)

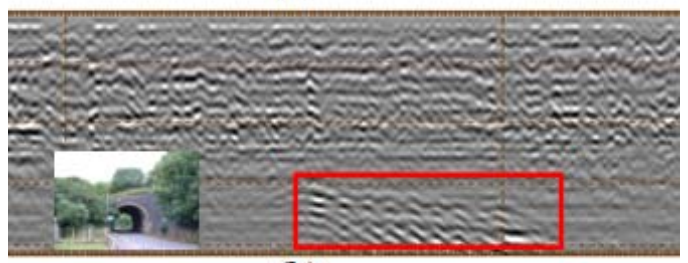

(b)

Figure 8. Civil structures identified in the GPR survey, including a bridge deck (a) and an underbridge (b).

\section{Evaluating Ballast Fouling}

Ballast fouling is an overall measure of the extent of fine particles contaminating the primary ballast layer. The wellknown Selig's fouling index quantifies the fouling by,

$$
F I=P_{4}+P_{200}
$$

where $P_{4}$ is the weight percentage of particles passing the 4.75 $\mathrm{mm}$ sieve and $P_{200}$ is the weight percentage of particles passing the $0.075 \mathrm{~mm}$ sieve [10]. Based on this, a qualitative classification of different ballast conditions are defined by Selig as in Table I.

TABLE I. RECOMMENDED FOULING CATEGORIES [10]

\begin{tabular}{|c|c|}
\hline Fouling category & Fouling index range \\
\hline Clean & FI $<1 \%$ \\
\hline Moderately Clean & $1 \%<=\mathrm{FI}<10 \%$ \\
\hline Moderately Fouled & $10 \%<=\mathrm{FI}<20 \%$ \\
\hline Fouled & $20 \%<=\mathrm{FI}<40 \%$ \\
\hline Highly Fouled & $40 \%<=\mathrm{FI}$ \\
\hline
\end{tabular}

According to the previously discussed scattering theory, GPR is capable of differentiating between ballast with and without air voids, which act as scatter of high frequency pulses. Based on this theory, Zetica have developed a GPR-derived ballast fouling index (BFI) which provides an estimate of the fouling without the requirement to physically sample the ballast [15]. The formula for calculating the BFI is obtained by the correlation between the scattering levels in the radar image with lab sieve analysis results of samples. The BFI represents a continuous measure along the survey line of the level of ballast fouling. It can also provide an averaged figure for a fixed interval. This has been proved to be extremely useful in trackbed maintenance and renewal planning.

The BFI has been verified against laboratory sampling results in a number of verification exercises. Table II lists the details of the most recent sampling program conducted in Wyoming, USA during 2009. A total of 32 ballast samples were taken from different locations along an 11 mile section of track.

Samples were analyzed in the laboratory for particle size distribution from which Selig's fouling index could be calculated using Formula 3. These results were plotted against the GPR-derived BFI to examine the correlation, as shown in Figure 9.

TABLE II. DETAILS OF THE WYOMING SAMPLING PROGRAM

\begin{tabular}{|l|l|}
\hline Total survey length & 11 miles \\
\hline $\begin{array}{l}\text { Total number of sample } \\
\text { locations }\end{array}$ & 32 \\
\hline
\end{tabular}




\begin{tabular}{|l|l|}
\hline $\begin{array}{l}\text { Number of samples on } \\
\text { track shoulders }\end{array}$ & 17 \\
\hline $\begin{array}{l}\text { Number of samples } \\
\text { taken on track center }\end{array}$ & 15 \\
\hline Sampling depth & 16 inches \\
\hline $\begin{array}{l}\text { Average weight of } \\
\text { samples }\end{array}$ & $31 \mathrm{~kg}$ \\
\hline
\end{tabular}

Sample locations were chosen to provide as wide a range of ballast fouling conditions as possible. Fouling index values are typically divided into five categories according Selig's recommendation (Table 1) and these have been used to colour each sample point in the figure. The dash line indicates the boundary between categories.

The results indicate a better than $87 \%$ correlation between the laboratory and GPR-derived fouling values indicating that GPR can be used as a reliable tool for determining ballast fouling, thus removing the need for costly ballast sampling or reliance on more subjective methods. This allows the railroad to more reliably determine where and when to undertake trackbed maintenance.

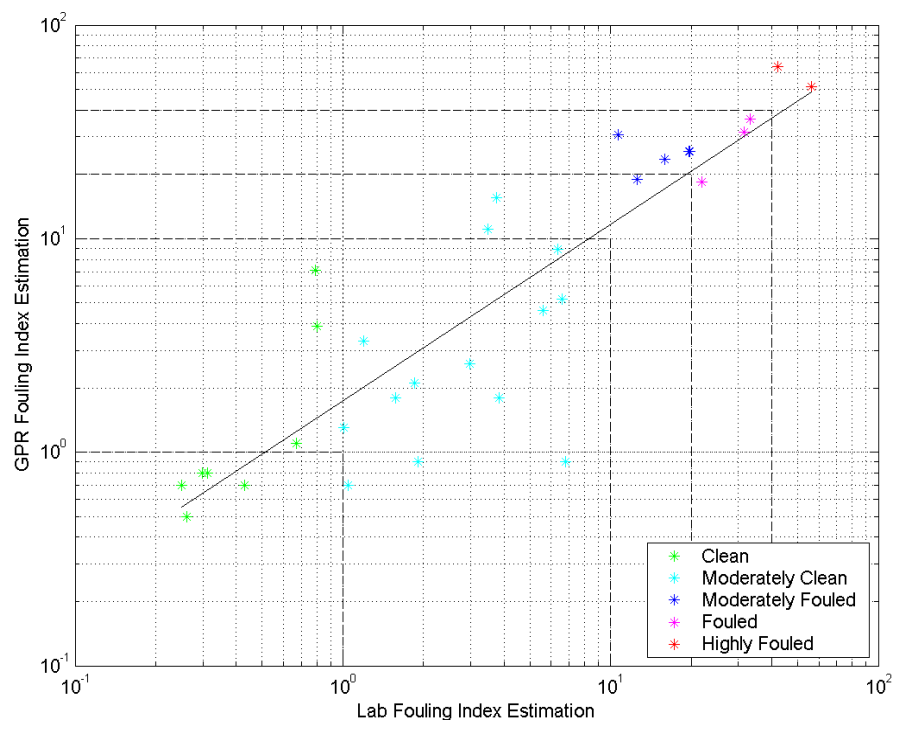

Figure 9. Correlation between the fouling index from sieve analysis and GPR-derived fouling index.

\section{CONCLUSIONS}

This paper has outlined various practical applications of GPR to assist track engineer to evaluate trackbed quality and identify problematic areas from the radar scans. Overall, GPR is a highly effective tool for trackbed condition evaluation and maintenance planning.

\section{REFERENCES}

[1] Hyslip, J.P., Smith, S.S., Olhoeft, G.R., and Selig, E.T., 2003, 'Assessment of Railway Track substructure Condition using Ground Penetrating Radar', AREMA, 5-7 Oct. 2003, Chicago, 20p.

[2] Olhoeft, G.R. and Selig, E.T., 2002, 'Ground Penetrating Radar Evaluation of Railroad Track Substructure Conditions', GPR 2002, 9th
Int'l. Conf. On Ground Penetrating Radar, Santa Barbara, CA, April 2002, S.K. Koppenjan and H.Lee, eds., Proc. SPIE vol. 4758, pp. 48-53.

[3] Eriksen, A., Gascoyne, J. and Al-Nuaimy, W., 'Improved Productivity and Reliability of Ballast Inspection using Road-Rail Multichannel GPR', Railway Engineering 2004, 6th - 7th, July 2004, Commonwealth Institute, London, UK.

[4] Gallagher, G.P., Leiper, Q.J. and Forde, M.C., 2000, 'How to Calibrate Radar Testing of Trackbed without Trial pits', Int'l. Railway Engineering Conf., 2000, London, UK.

[5] Eriksen, A.,Venables, B., Gascoyne, J., and Bandyopadhyay, S., 2006 , 'Benefits of high speed GPR to manage trackbed assets and renewal strategies', PWI Conference, June 2006, Brisbane, Australia.

[6] Shihab, S., Al-Nuaimy, W., Huang, Y. and Eriksen, A., 'Neural Network Target Identifier based on Statistical Features of GPR Signals', International conference on ground penetrating radar, 9th, 2002, vol. 4758, pp. 135-138.

[7] Edited by David J. Daniels, Ground Penetrating Radar 2nd Edition, IEE Radar, Sonar and Navigation series 15, 2004.

[8] Gallapher, G.P., Leiper, Q., Clark, M.R., and Forde, M. C., Identification of railway trackbed anomalies using monostatic GPR reflection techniques, Railway Engineering 99, London 1999.

[9] Roberts, R., Al-Qadi, I., Tutumluer, E., Boyle, J., and Sussmann, T., Advances in railroad ballaste valuation using $2 \mathrm{GHz}$ horn antennas, 11 th Internationl Conference on Ground Penetrating Radar, Juen 19-22, 2006, Columbus Ohio, USA.

[10] Selig, E.T. and Waters, J.W. (1994). Track geotechnology and substructure management. Thomas Telford Ltd., London.

[11] Al-Qadi, I.L., Xie, Q. and Roberts, R., 'Scattering Analysis of Railroad Ballast using Ground Penetrating Radar', Transportation Research Board 86th Annual Meeting, 2007, Washington D.C.

[12] Zhang, Q., Gascoyne, J., Eriksen, A., Recent advances in the application of GPR for trackbed characterisation, 12th international conference on Ground Penetrating Radar, June 16-19, 2008, Birmingham, UK.

[13] David C. Nobes, Emma F. Davis and Steven A. Arcone, "Mirror-image" multiples in ground-penetrating radar, Geophysics, vol. 70, no. 1(Janurary-Feburary); P. K20-K22.

[14] Olhoeft, G.R., 2003, 'Electromagnetic Field and Material properties in Ground Penetrating Radar', Proc. 2nd Int'l. Workshop on Advanced GPR, 14-16 May 2003, Delft, The Netherlands, A.Yarovoy, ed., p.144 147.

[15] Benefits of routine ballast inspection using ZARR-Zetica's Advanced Rail Radar, Zetica white paper, www.zetica.com. 